\title{
Article \\ Boosting pH-Universal Hydrogen Evolution of FeP/CC by Anchoring Trace Platinum
}

\author{
Chuancang Zhou ${ }^{1}$, Feipeng Zhang ${ }^{2,3, *}$ and Hongyu $\mathrm{Wu}^{1, *}$
}

1 College of Engineering, Lishui University, Lishui 323000, China; 30130815@hncj.edu.cn

2 Henan Provincial Engineering Laboratory of Building-Photovoltaics, Institute of Physics, Henan University of Urban Construction, Pingdingshan 467036, China

3 School of Materials Sciences and Engineering, Shijiazhuang Tiedao University, Shijiazhuang 050043, China

* Correspondence: zhfp@emails.bjut.edu.cn (F.Z.); zhoucc@lsu.edu.cn (H.W.)

Citation: Zhou, C.; Zhang, F.; Wu, H. Boosting $\mathrm{pH}$-Universal Hydrogen Evolution of FeP/CC by Anchoring Trace Platinum. Crystals 2022, 12, 37. https://doi.org/10.3390/cryst12010037
Received: 29 October 2021

Accepted: 24 December 2021

Published: 27 December 2021

Publisher's Note: MDPI stays neutral with regard to jurisdictional claims in published maps and institutional affiliations.

Copyright: () 2021 by the authors. Licensee MDPI, Basel, Switzerland. This article is an open access article distributed under the terms and conditions of the Creative Commons Attribution (CC BY) license (https:// creativecommons.org/licenses/by/ $4.0 /)$.

\begin{abstract}
To improve the electrocatalytic properties for hydrogen evolution reactions, strategies need to be adopted, such as increasing specific surface area and active site, as well as decreasing interface energy. Herein, we report the preparation of FeP on carbon cloth using a two-step process of hydrothermal and phosphating. Otherwise, to utilize the excellent catalytic performance of Pt and decrease consumption of $\mathrm{Pt}$, the hyperdispersed $\mathrm{Pt}$ nanoparticles for the sake of modifying transitionmetal phosphides film were designed and fabricated. Finally, 3D FeP-Pt/CC was successfully prepared by means of electro-deposition using three electrodes. The crystalline structure, surface morphology and elemental composition of the synthesized samples have been investigated by X-ray diffraction (XRD), X-ray photoelectron spectroscopy (XPS), scanning electron microscopy (SEM) and energy dispersive $\mathrm{X}$-ray analysis (EDS). The XRD results show that the as-prepared products are of orthorhombic FeP structure, and EDS results indicate that there exist Pt elements in 3D FeP-Pt/CC. The electrocatalytic performances were evaluated by, such as linear scan voltammetry, tafel plots and electrochemical impedance spectroscopy on electrochemical workstations. These results show that the FeP-Pt/CC exhibit a current density of $10 \mathrm{~mA} \cdot \mathrm{cm}^{-2}$ at an over-potential of $58 \mathrm{mV}$ for HER in $0.5 \mathrm{M} \mathrm{H}_{2} \mathrm{SO}_{4}$, which is very close to the values of $20 \% \mathrm{Pt} / \mathrm{C}$ which was previously reported. $\mathrm{FeP}-\mathrm{Pt} / \mathrm{CC}$ has excellent durability.
\end{abstract}

Keywords: FeP-Pt/CC; hydrogen evolution reaction; electrochemical impedance spectroscopy; durability

\section{Introduction}

With the increasing depletion of fossil fuels and tremendous environmental pollution, hydrogen energy is extensively concerned as it is a clean, highly efficient and renewable energy alternative [1-6]. Electrochemical water splitting is considered to be one of the most promising large-scale hydrogen production methods. However, the industrialization of water electrolysis is still limited due to the lack of cheap and efficient catalysts [7-10]. Among the numerous catalysts, transition-metal phosphides with high conductivity, chemical stability, special crystal structure and abundant valence state have been intensively focused. To improve the electrocatalytic performances, an important strategy is increasing the number of active sites by means of generating a larger specific surface area [11-14]. Besides, three dimension (3D) basal electrodes, for example, carbon cloth has excellent conductivity, mechanical properties and larger specific surface area [15]. At present, Pt metal is regarded to be the most efficient electrocatalyst for hydrogen evolution reactions [9]. However, the resource of $\mathrm{Pt}$ is scarce and expensive. In this report, the hyperdispersed $\mathrm{Pt}$ nanoparticles for the sake of modifying transition-metal phosphides film is designed and fabricated in order to utilize the catalytic performance of $\mathrm{Pt}$ and reduce $\mathrm{Pt}$ dosage at the same time. The 3D FeP-Pt film was grown on conductive carbon cloth (CC) by means of hydrothermal methods with high temperature phosphating and electro-deposition $[5,7,8]$. 
The results show FeP-Pt/CC has excellent electrocatalytic performances for HER at all $\mathrm{pH}$ and has excellent durability and long term stability.

\section{Experimental}

Firstly, the CC matrix with an area of $1 \mathrm{~cm} \times 1 \mathrm{~cm}$ is hydrothermally treated in $68 \%$ $\mathrm{HNO}_{3}$ solution at $120{ }^{\circ} \mathrm{C}$, and then it is washed by deionized water and electrochemically oxidized for 30 mins in $\mathrm{NaCl}$ solution. The solution of Ferric nitrate, ammonium fluoride and carbamide was prepared in a reactor, and then the treated CC matrix was placed in the solution at $120^{\circ} \mathrm{C}$ for $12 \mathrm{~h}$. Iron compound film attached to carbon cloth obtained after cooled and washed. The iron compound film was then dried at $100^{\circ} \mathrm{C}$ and subjected to sintering in succession at $300-350^{\circ} \mathrm{C}$ for $2-3 \mathrm{~h}$ in a tube furnace with argon and sodium hypophosphite to obtain the FeP/CC. Finally, the Platinum nanoparticles were prepared on the FeP/CC by electrodeposition on FeP/CC, and then the 3D FeP-Pt/CC was obtained. It is electrodeposited for $2 \mathrm{~h}$ under the voltage of $-0.6--0.7 \mathrm{~V}$ in the solution of potassium chloroplatinate and a small amount of boric acid.

The X-ray diffraction (XRD) measurements were carried out by using a Dandong DX-2700B diffractometer with CuKa radiation $(\lambda=1.5418 \AA)$. The scanning electron microscopy (SEM) images were obtained by scanning electron microscopy (VEGA3, TESCAN, Brno, South Moravia, Czech Republic). The X-ray photoelectron spectroscopes (XPS) were carried out (ESCALAB 250Xi, Al Ka, $150 \mathrm{~W}$, Waltham, MA, USA) to examine the chemical composition and valence state of the as-prepared samples. The electrochemical measurements were performed with a three-electrode system in $0.5 \mathrm{M} \mathrm{H}_{2} \mathrm{SO}_{4}, 1 \mathrm{M} \mathrm{PBS}$ (Phosphate buffer solution), $1 \mathrm{M} \mathrm{KOH}$ solution using a princeton electrochemical workstation. A saturated calomel electrode (SCE) and a graphite rod were used as the reference electrode and counter electrode, respectively in acidic and neutral solutions. $\mathrm{Hg} / \mathrm{HgO}$ is used as reference electrodes in alkaline solution. The as-prepared FeP-Pt/CC was used as the working electrode. The linear scan voltammetry (LSV) measurements were carried at a scanning rate of $5 \mathrm{mVs}^{-1}$. The electrochemical impedance spectra (EIS) were obtained at $-200 \mathrm{mV}$ vs reference electrode with a frequency range from $0.1 \mathrm{~Hz}$ to $100,000 \mathrm{~Hz}, 5 \mathrm{mg}$ $20 \% \mathrm{Pt} / \mathrm{C}$ catalyst, add $100 \mu \mathrm{L} 5 \mathrm{w} \%$ Nafion solution and $900 \mu \mathrm{L}$ ethanol and mix with ultrasound for at least $30 \mathrm{~min} ; 1 \mu \mathrm{L}$ of solution suck each time and drop it onto the glassy carbon electrode (with a diameter of $3 \mathrm{~mm}$ ), drop it again after drying, and until the loading capacity is $0.212 \mathrm{mg} / \mathrm{cm}^{2}$. All the measurements were corrected using iR compensation.

\section{Results and Discussion}

The XRD patterns of the FeP-Pt/CC and FeP/CC are shown in Figure 1. It can be seen from Figure 1 that all the samples before and after electro-deposition (FeP/CC and FeP-Pt/CC) can be well indexed as the orthorhombic FeP (JCPDS No. 390809) phase. It is evidenced that the FeP was well prepared. It can be seen from the figure that after the electrodeposition of platinum, the crystallinity and purity of the film decreased. In addition, the diffraction peaks of Platinum shown in the XRD pattern of FeP-Pt/CC in Figure 1 at $39.77^{\circ}, 46.26^{\circ}$ indicate that there has $\mathrm{Pt}$ metal in FeP-Pt/CC.

The SEM and edx mapping images of the FeP-Pt/CC and FeP/CC films are shown in Figures 2 and 3. It can be seen from the scanning electron microscope that the surface grains of the film before electrodeposition are mainly composed of rods with a diameter of less than 1 micron, and massive grains with a size of several microns appear after electrodeposition. According to the EDX diagram, the molar ratio of Fe:P:Pt is about 16.45:18.9:4.87 and there are some impurities of $\mathrm{NaCl}$. According to EDX mapping photos, $\mathrm{Fe}, \mathrm{P}, \mathrm{Pt}$ has similar element distribution, indicating the dispersion uniformity of $\mathrm{Pt}$, and a small amount of oxidation points can be seen. It can also be seen from Figure 3 that there have not been Pt elements in the FeP/CC particles and the molar ratio of Fe:P is 18.58:25.76. It is evidenced that the FeP-Pt/CC was successfully obtained. 


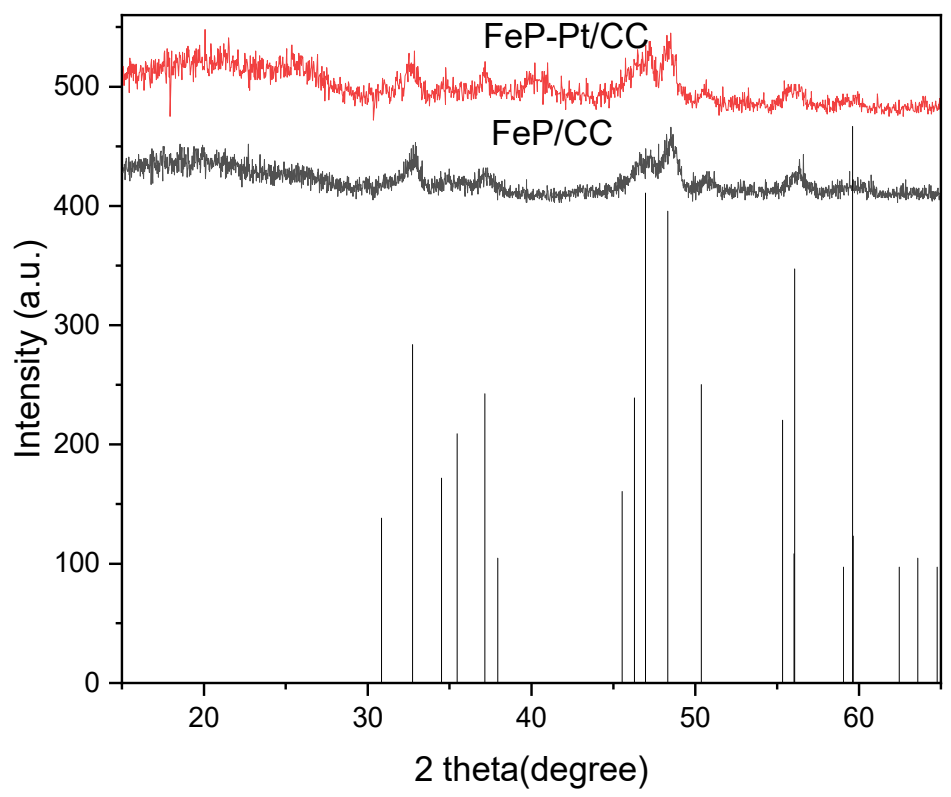

Figure 1. XRD patterns of the FeP/CC and FeP-Pt/CC.

In order to further verify the composition of the FeP-Pt/CC film surface, the X-ray photoelectron spectroscopy (XPS) survey is used. Figure 4 presents the XPS results of the FeP-Pt/CC. As shown in the figure, the total spectrum suggests the co-existence of Carbon, Oxygen, Ferrum, Phosphorus and Platinum element in the material. The Fe $2 p_{3 / 2}$ corresponds to peak at $712 \mathrm{eV}$ and the $\mathrm{Fe} 2 \mathrm{p}_{1 / 2}$ corresponds to peak at $726 \mathrm{eV}$. The P $2 \mathrm{p}$ corresponds to one peak at $134 \mathrm{eV}$ and P $2 \mathrm{~s}$ corresponds to the peak at $192 \mathrm{eV} ; 71.6 \mathrm{eV}$ and $75.16 \mathrm{eV}$ of the peak corresponds to zero valences of Pt. Besides, the $\mathrm{C} 1 \mathrm{~s}$ and $\mathrm{O}$ 1 s correspond to the peaks at $280 \mathrm{eV}$ and $531.9 \mathrm{eV}$, respectively. The OKL1 and OKL2 correspond to peaks at $990 \mathrm{eV}$ and $1000 \mathrm{eV}$. It is well evidenced that the FeP-Pt/CC was successfully fabricated with a small amount of precious Pt.

The electrocatalytic performances of FeP-Pt/CC and FeP/CC were investigated by a Princeton electrochemical workstation. All HER measurements were carried out at $25{ }^{\circ} \mathrm{C}$. The results are given in Figure 5. It can be seen from Figure 5a that FeP-Pt/CC and $\mathrm{FeP} / \mathrm{CC}$ possesses over-potentials of $-58 \mathrm{mV}$ and $-110 \mathrm{mV}$ reach the cathode current density of $10 \mathrm{~mA} \cdot \mathrm{cm}^{-2}$ in $0.5 \mathrm{M} \mathrm{H}_{2} \mathrm{SO}_{4}$, while $20 \% \mathrm{Pt} / \mathrm{C}$ has the smallest $\eta_{10}(-36 \mathrm{mV})$. Their corresponding Tafel slope is $49.6,70.6,108.6 \mathrm{mV} / \mathrm{dec}$. Tafel slopes suggest that the Volmer reaction is fast and the rate-limiting step is the Heyrovsky reaction. It shows that the addition of platinum greatly improves the hydrogen evolution performance of $\mathrm{FeP}$. However, in the phosphate buffer solution, the hydrogen evolution performance is poor, $\eta_{10}$ of FeP-Pt/CC, FeP/CC and Pt/C is $-214,-187,-60 \mathrm{mV}$, respectively. The corresponding Tafel slope are 256, 510, $105.5 \mathrm{mV} / \mathrm{dec}$. At a higher potential, platinum can improve the HER performance of FeP greatly, even more than $20 \% \mathrm{Pt} / \mathrm{C}$. A neutraleffective electrocatalyst has apparently the best benefit of environmental benignity and very broad application prospects. Alkaline-efficient electrocatalysts are the most important and widely used technology in the industry. From Figure 5 e, we can find that $20 \% \mathrm{Pt} / \mathrm{C}$ exhibits excellent electrocatalytic activity in $1 \mathrm{~m} \mathrm{KOH} . \eta_{10}$ of FeP-Pt/CC and FeP/CC are $-42.6,-44 \mathrm{mV}$, respectively. The corresponding Tafel slopes are $80,60.5 \mathrm{mV} / \mathrm{dec}$. LSV of FeP-Pt/CC has been very close to Pt/C catalyst. It shows that FeP-Pt/CC has a good application prospect. 

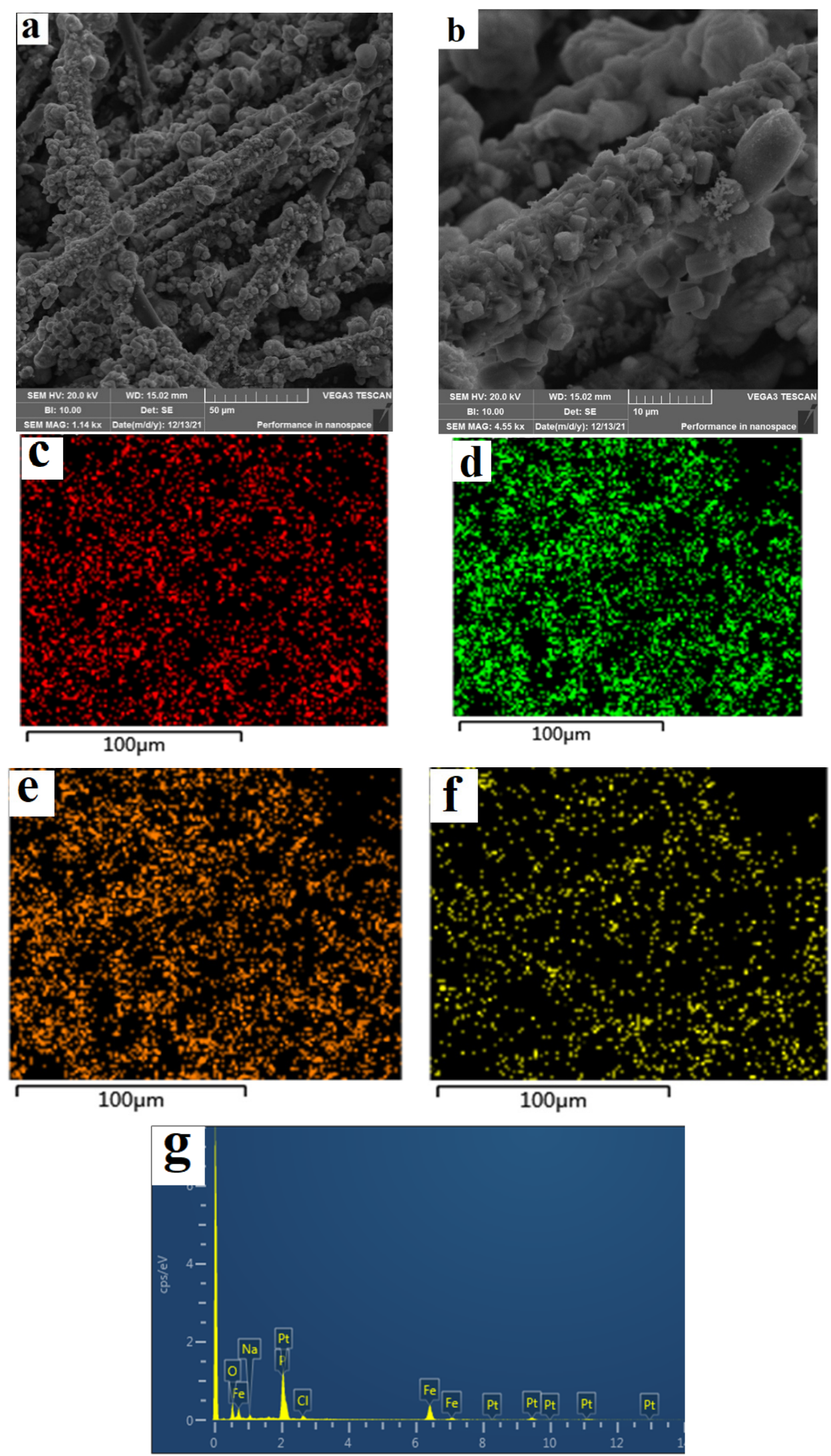

Figure 2. SEM images (a,b), EDX mapping (c-f) and EDX spectrum (g) of FeP-Pt/CC. 

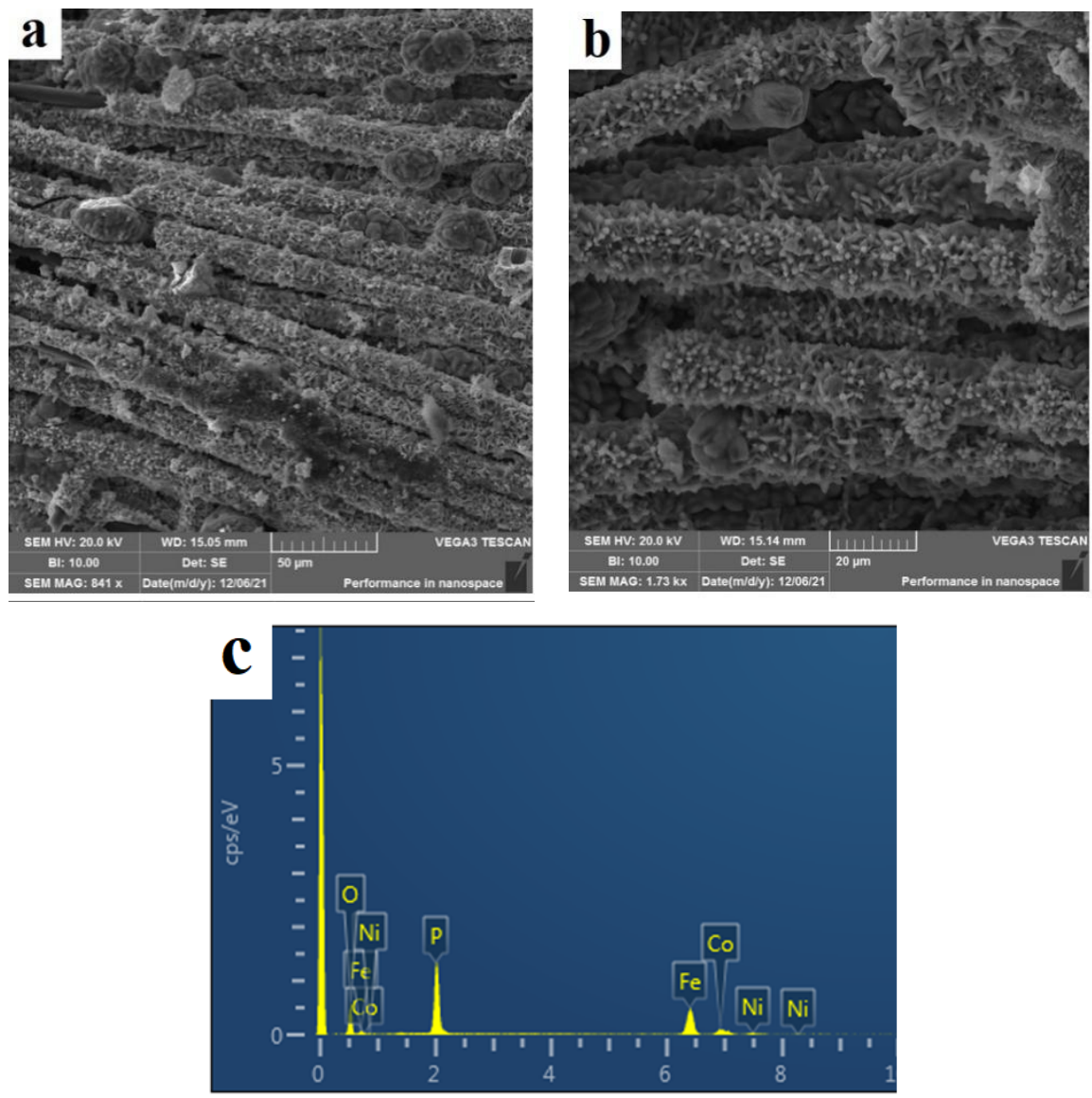

Figure 3. SEM images (a,b) and EDX spectrum (c) of FeP/CC.
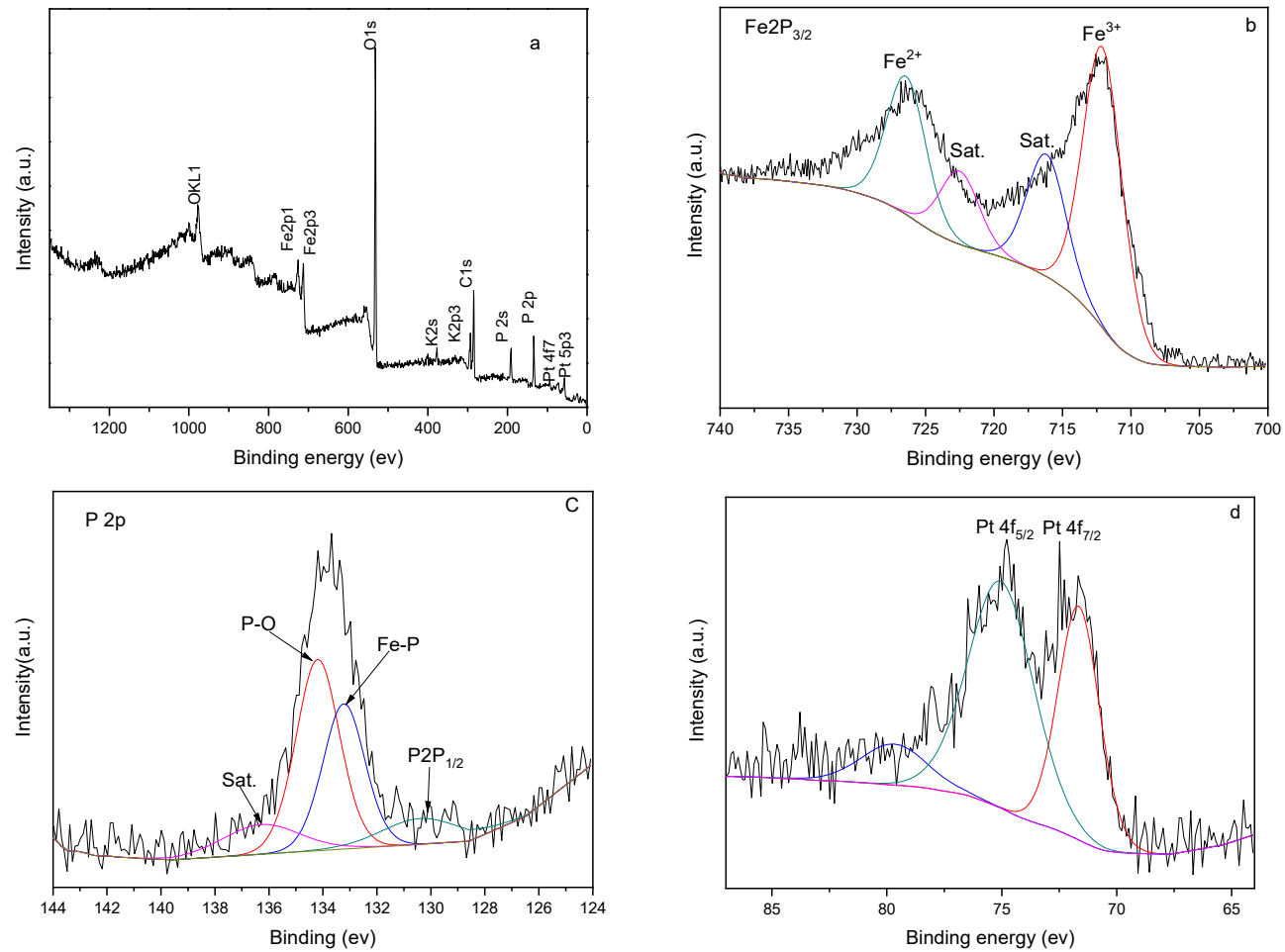

Figure 4. XPS spectra of FeP-Pt/CC (a) survey spectrum, (b) Fe 2p, (c) P 2p and (d) Pt 4f. 

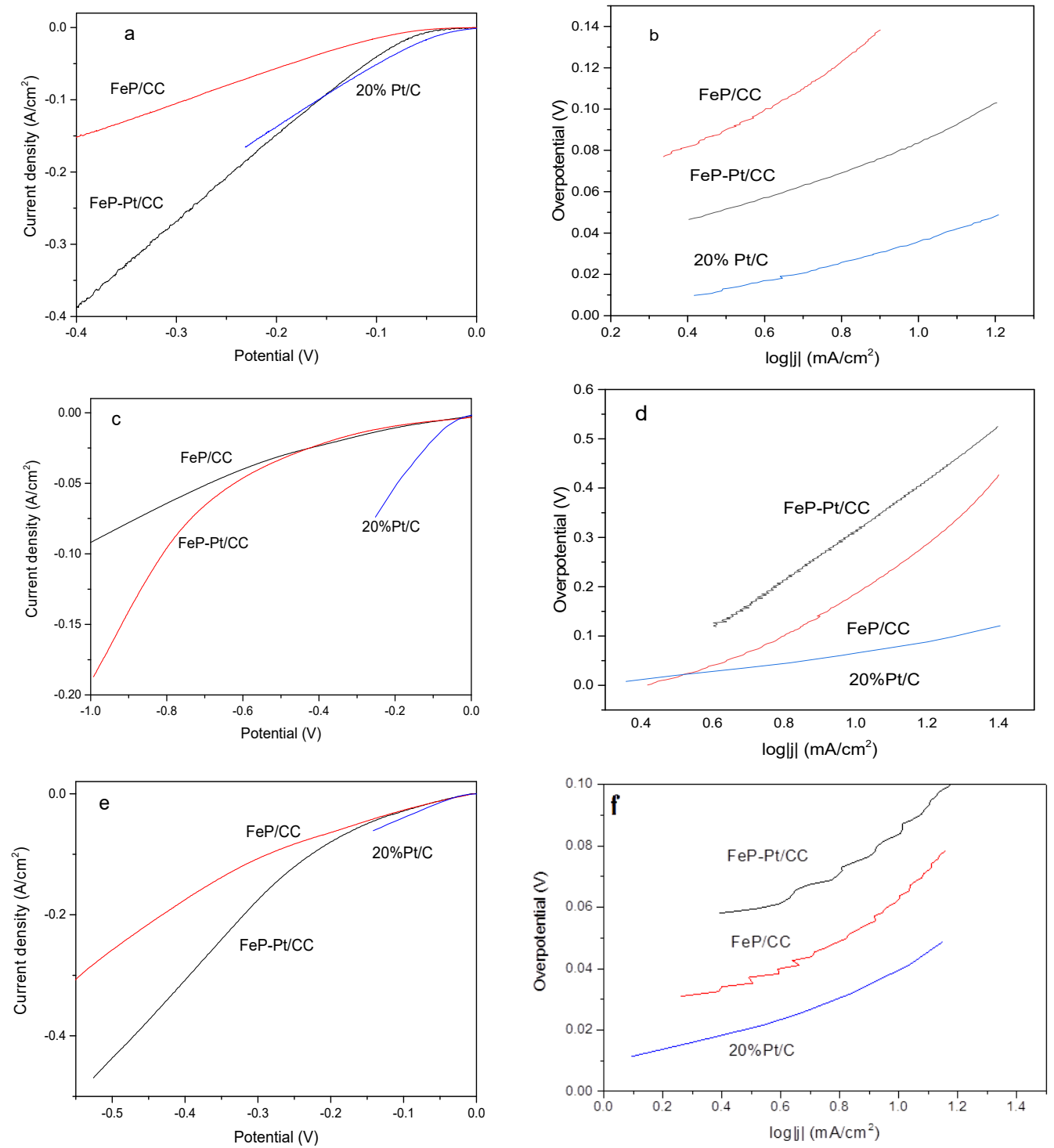

Figure 5. Electrochemical HER measurements. Linear sweep polarization curves obtained in $0.5 \mathrm{M} \mathrm{H}_{2} \mathrm{SO}_{4}(\mathbf{a}), 1 \mathrm{M}$ PBS (c), $1 \mathrm{M} \mathrm{KOH}(\mathbf{e})$. The corresponding Tafel slopes (b,d,f).

To further investigate the electrocatalytic performances of the materials, electrochemical impedance spectroscopy is also carried out. Figure 6 shows the results of Nyquist plots of FeP-Pt/CC and FeP/CC at $-0.2 \mathrm{~V}$ in $0.5 \mathrm{M} \mathrm{H}_{2} \mathrm{SO}_{4}$. Table 1 shows the element values in the equivalent circuit of the AC impedance spectrum. It can be found from Figure 6 that the Nyquist plot shows a line with an angle of inclination of $45^{\circ}$, which suggests the phase angle of reactive ions concentration fluctuation on the electrode surface is 45 degrees lags behind the AC current. In addition, it can be seen from Table 1 that the R1 (reactive resistance) of FeP-Pt/CC is $0.75 \Omega$, which is very much less than that of FeP/CC (1.6 $\Omega$ ). These features indicate that the electrode reaction is completely controlled by the diffusion step. It is estimated that the reason is Platinum particles reduce the reactive resistance and make the surface rougher. 


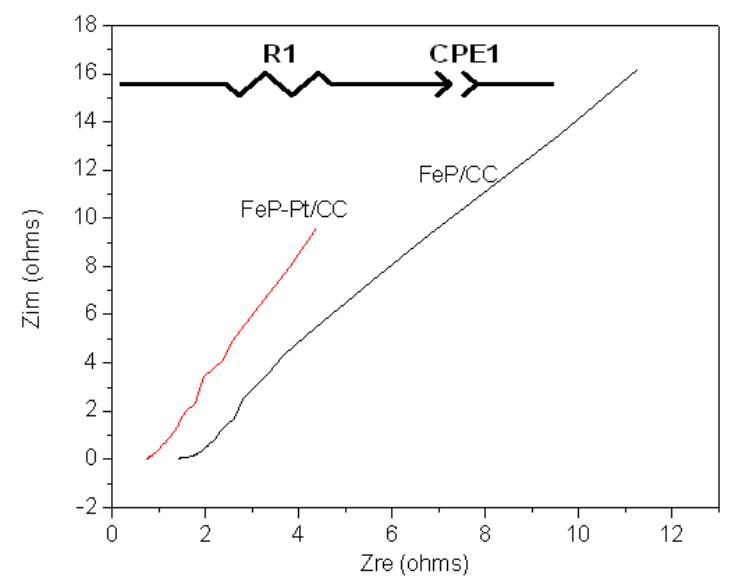

Figure 6. Nyquist plots of FeP-Pt/CC and FeP/CC at $-0.2 \mathrm{~V}$ in $0.5 \mathrm{M} \mathrm{H}_{2} \mathrm{SO}_{4}$ with inset the equivalent electrical circuit.

Table 1. Element values in the equivalent circuit of $\mathrm{AC}$ impedance spectrum in $0.5 \mathrm{M} \mathrm{H}_{2} \mathrm{SO}_{4}$.

\begin{tabular}{ccc}
\hline Element & FeP-Pt/CC & FeP/CC \\
\hline $\mathrm{R} 1 / \Omega$ & 0.75157 & 1.603 \\
\hline $\mathrm{CPE} 1-\mathrm{T} / \Omega^{-1} \cdot \mathrm{cm}^{-2} \cdot \mathrm{s}^{-\mathrm{n}}$ & 0.15453 & 0.086979 \\
\hline $\mathrm{CPE} 1-\mathrm{P} / \Omega^{-1} \cdot \mathrm{cm}^{-2} \cdot \mathrm{s}^{-\mathrm{n}}$ & 0.74181 & 0.70683 \\
\hline
\end{tabular}

Figure 7 shows the results of Nyquist plots of FeP-Pt/CC and FeP/CC at $-0.2 \mathrm{~V}$ in $1 \mathrm{M} \mathrm{KOH}$ with an inset of the equivalent electrical circuit. It can be seen from Figure 7 that the inclined straight lines show an angle of nearly 45 degrees, this suggests that there is a thick and compact passivation film on the surface of the electrode, and the ion migration is greatly inhibited. These results indicate that a dense passivation film is easily formed on the surface of iron in a strongly alkaline solution. It can also be deduced that the circuit diagram is a series connection of resistor R1 and constant phase element (CPE). Here the constant phase element CPE has two values, CPE-P and CPE-T. Table 2 shows the element values in the equivalent circuit of the AC impedance spectrum. As is shown in Table 2, the CPE-P values of FeP-Pt/CC and FeP/CC are $0.7778 \Omega^{-1} \cdot \mathrm{cm}^{-2} \cdot \mathrm{s}^{-\mathrm{n}}$ and $0.7689 \Omega^{-1} \cdot \mathrm{cm}^{-2} \cdot \mathrm{s}^{-\mathrm{n}}$, respectively. It can be illustrated that the rough and porous electrode surface produces double-layer capacitance and there exists a dispersion effect on the electrode surface. The resistance should decrease because platinum has better conductivity than FeP after platinum plating. In addition, the increase of $\mathrm{CPE}$ value indicates the increase of capacitance effect and the increase of film thickness and roughness.

In addition, the durability and long term stability of materials were further investigated. Figure 8 shows the V-T curve of FeP-Pt/CC at $10 \mathrm{~mA} / \mathrm{cm}^{2}$ in $0.5 \mathrm{M} \mathrm{H}_{2} \mathrm{SO}_{4}, 1 \mathrm{M}$ PBS, $1 \mathrm{M} \mathrm{KOH}$, respectively. Compared with other solutions, potential changes little in the $0.5 \mathrm{M} \mathrm{H}_{2} \mathrm{SO}_{4}$. In general, the potential changes little after $20 \mathrm{~h}$ in various solutions, which can be applied in practical production. 


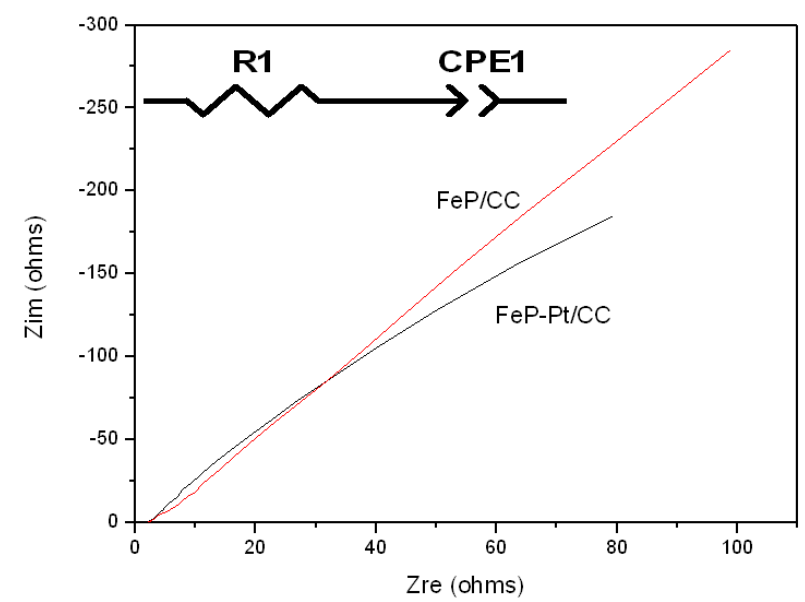

Figure 7. Nyquist plots of FeP-Pt/CC and FeP/CC at $-0.2 \mathrm{~V}$ in $1 \mathrm{M} \mathrm{KOH}$. The inset is the equivalent electrical circuit.

Table 2. Element values in the equivalent circuit of AC impedance spectrum in $1 \mathrm{M} \mathrm{KOH}$.

\begin{tabular}{ccc}
\hline Element & FeP-Pt/CC & FeP/CC \\
\hline $\mathrm{R} 1 / \Omega$ & 1.827 & 2.184 \\
\hline $\mathrm{CPE} 1-\mathrm{T}\left(\Omega^{-1} \cdot \mathrm{cm}^{-2} \cdot \mathrm{s}^{-\mathrm{n}}\right)$ & 0.00795 & 0.00551 \\
\hline $\mathrm{CPE} 1-\mathrm{P}\left(\Omega^{-1} \cdot \mathrm{cm}^{-2} \cdot \mathrm{s}^{-\mathrm{n}}\right)$ & 0.7778 & 0.7689 \\
\hline
\end{tabular}
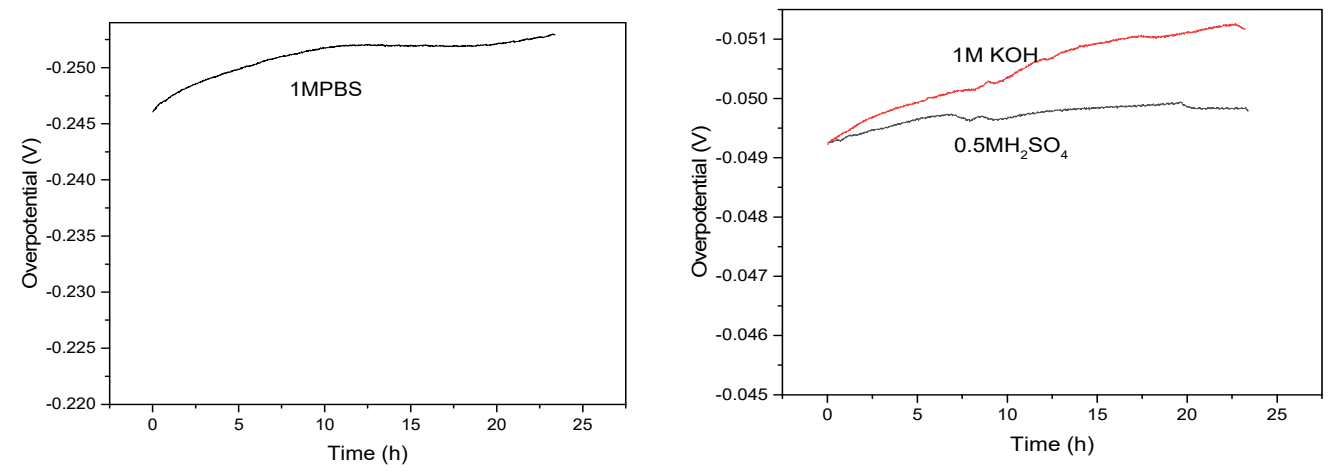

Figure 8. Time dependence of Overpotential for $\mathrm{NiCo}_{2} \mathrm{P}_{\mathrm{x}}$ at $10 \mathrm{~mA} / \mathrm{cm}^{2}$ (in $0.5 \mathrm{M} \mathrm{H}_{2} \mathrm{SO}_{4}, 1 \mathrm{M} \mathrm{KOH}$ and 1 M PBS).

\section{Conclusions}

FeP-Pt/CC has also been successfully prepared by means of hydrothermal-phosphatization and electrodeposition methods. The as-prepared FeP films have an orthorhombic structure. XPS and EDX tests proved the uniform distribution of $\mathrm{Pt}$ in FeP-Pt/CC, the addition of trace platinum can significantly improve the catalytic activity of $\mathrm{FeP}$ for hydrogen evolution. FeP-Pt/CC exhibit a current density of $10 \mathrm{~mA} \cdot \mathrm{cm}^{-2}$ at over-potential of $58 \mathrm{mV}$ and $42.6 \mathrm{mV}$ for HER in $0.5 \mathrm{M} \mathrm{H}_{2} \mathrm{SO}_{4}$ and $1 \mathrm{M} \mathrm{KOH}$, respectively, this is very close to the values of $20 \%$ $\mathrm{Pt} / \mathrm{C}$ V-t curves with $20 \mathrm{~h}$ in various solutions show FeP-Pt/CC has excellent durability and long term stability.

Author Contributions: Conceptualization, F.Z.; methodology, C.Z.; formal analysis, C.Z. and F.Z.; resources, H.W.; data curation, C.Z.; writing-original draft preparation, C.Z.; writing-review and editing, F.Z.; visualization, F.Z.; supervision, F.Z. and H.W.; project administration, H.W.; funding acquisition, H.W. All authors have read and agreed to the published version of the manuscript.

Funding: The authors would like to thank the support provided by National Natural Science Foundation of China under grant No.51572066. 
Data Availability Statement: The datasets generated during and/or analyzed during the current study are available from the corresponding author on reasonable request.

Conflicts of Interest: Authors declare that they have no known competing financial interests or personal relationships that could have appeared to influence the work reported in this paper.

\section{References}

1. Niu, Z.; Qiu, C.; Jiang, J.; Ai, L. Hierarchical CoP-FeP Branched Heterostructures for Highly Efficient Electrocatalytic Water Splitting. ACS Sustain. Chem. Eng. 2018, 7, 2335. [CrossRef]

2. Anantharaj, S.; Ede, S.R.; Sakthikumar, K.; Karthick, K.; Mishra, S.; Kundu, S. Electrospun cobalt-ZIF micro-fibers for efficient water oxidation under unique $\mathrm{pH}$ conditions. ACS Catalysis 2016, 6, 8069. [CrossRef]

3. Liu, T.; Ma, X.; Liu, D.; Hao, S.; Du, G.; Ma, Y.; Asiri, A.M.; Sun, X.; Chen, L. Mn Doping of CoP Nanosheets Array: An Efficient Electrocatalyst for Hydrogen Evolution Reaction with Enhanced Activity at All pH Values. ACS Catalysis 2017, 7, 98. [CrossRef]

4. Guo, P.; Wu, Y.X.; Lau, W.M.; Liu, H. Porous CoP nanosheet arrays grown on nickel foam as an excellent and stable catalyst for hydrogen evolution reaction. Int. J. Hydrog. Energy 2017, 42, 26995. [CrossRef]

5. Yan, Y.; Thia, L.; Xia, B.Y.; Ge, X.; Liu, Z.; Fisher, A.; Wang, X. Construction of Efficient 3D Gas Evolution Electrocatalyst for Hydrogen Evolution: Porous FeP Nanowire Arrays on Graphene Sheets. Adv. Sci. 2015, 2, 1500120. [CrossRef] [PubMed]

6. Sun, Y.; Hang, L.; Shen, Q.; Zhang, T.; Li, H.; Zhang, X.; Lyue, X.; Li, Y. Mo doped Ni2P nanowire arrays: An efficient electrocatalyst for the hydrogen evolution reaction with enhanced activity at all $\mathrm{pH}$ values. Nanoscale 2017, 9, 16674. [CrossRef] [PubMed]

7. Zhang, J.; Liang, X.; Wang, X.; Zhuang, Z. CoP nanotubes formed by Kirkendall effect as efficient hydrogen evolution reaction electrocatalysts. Mater. Lett. 2017, 202, 146. [CrossRef]

8. Zhang, R.; Wang, X.; Yu, S. Ternary NiCo2Px Nanowires as pH-Universal Electrocatalysts for Highly Efficient Hydrogen Evolution Reaction. Adv. Mater. 2017, 29, 1605502. [CrossRef] [PubMed]

9. Jiang, K.; Liu, B.; Luo, M. Single platinum atoms embedded in nanoporous cobalt selenide as electrocatalyst for accelerating hydrogen evolution reaction. Nat. Commun. 2019, 10, 1743. [CrossRef] [PubMed]

10. Li, Y.; Cai, P.; Ci, S.; Wen, Z. Strongly Coupled 3D Nanohybrids with Ni2P/Carbon Nanosheets as pH-Universal Hydrogen Evolution Reaction Electrocatalysts. ChemElectroChem 2017, 4, 340. [CrossRef]

11. Feng, J.X.; Tong, S.Y.; Tong, Y.X.; Li, G.R. Pt-like Hydrogen Evolution Electrocatalysis on PANI/CoP Hybrid Nanowires by Weakening the Shackles of Hydrogen Ions on the Surfaces of Catalysts. J. Am. Chem. Soc. 2018, 140, 5118. [CrossRef] [PubMed]

12. Liu, Z.; Qi, J.; Liu, M.; Zhang, S.; Fan, Q.; Liu, H.; Liu, K.; Zheng, H.; Yin, Y.; Gao, C. Aqueous Synthesis of Ultrathin Platinum/NonNoble Metal Alloy Nanowires for Enhanced Hydrogen Evolution Activity. Angew. Chem. 2018, 130, 11852. [CrossRef]

13. Ma, J.; Habrioux, A.; Alonso-Vante, N. Enhanced HER and ORR behavior on photodeposited Pt nanoparticles onto oxide-carbon composite. J. Solid State Electrochem. 2013, 17, 1913. [CrossRef]

14. Spori, C.; Kwan, J.T.H.; Bonakdarpour, A.; Wilkinson, D.; Strasser, P. Analysis of oxygen evolving catalyst coated membranes with different current collectors using a new modified rotating disk electrode technique. Angew. Chem. Int. Ed. Eng. 2017, $56,5994$.

15. Wang, Y.; Li, M.; Xu, L.; Tang, T.; Ali, Z.; Huang, X.; Hou, Y.; Zhang, S. Polar and conductive iron carbide@N-doped porous carbon nanosheets as a sulfur host for high performance lithium sulfur batteries. Chem. Eng. J. 2019, 358, 962. [CrossRef] 